\title{
Tremors along the Queen Charlotte Margin triggered by large teleseismic earthquakes
}

\author{
Chastity Aiken, ${ }^{1}$ Zhigang Peng, ${ }^{1}$ and Kevin $\mathrm{Chao}^{2}$ \\ Received 20 November 2012; revised 30 January 2013; accepted 2 February 2013; published 14 March 2013.
}

[1] We conduct a systematic search of tectonic tremors along the Queen Charlotte Margin (QCM) in western Canada triggered by distant earthquakes. We identify triggered tremor as non-impulsive, high-frequency signals coherent among several stations and coincident with passing surface waves. So far, the $2002 M_{w} 7.9$ Denali Fault, the $2004 M_{w} 9.2$ Sumatra, and the $2011 M_{w} 9.1$ Tohoku-Oki earthquakes have triggered clear tremor in this region. The $2010 M_{w} 8.8$ Maule, Chile and the $2012 M_{w} 8.6$ Sumatra earthquakes may have triggered, but tremors in these two cases did not meet all of our criteria. The triggered tremors are mostly located east of the Queen Charlotte Fault in the southern portion of Haida Gwaii, near the epicenter of the 28 October $2012 M_{w} 7.7$ earthquake. Similar to the observations in other regions, the triggered tremors were initiated by the Love waves and continued during the subsequent Rayleigh waves. Tremor bursts correlate with both the particle velocity and displacement of the Love waves, indicating they are triggered at either low-angle thrust or vertical strike-slip faults. In addition, we find that the triggering potential for the QCM is controlled by a combination of amplitude, period, and incident angles. Citation: Aiken, C., Z. Peng, and K. Chao (2013), Tremors along the Queen Charlotte Margin triggered by large teleseismic earthquakes, Geophys. Res. Lett., 40, 829-834, doi:10.1002/grl.50220.

\section{Introduction}

[2] Deep tectonic tremors have been observed along subduction zones around the Pacific plate [Peng and Gomberg, 2010; Beroza and Ide, 2011], within the arc-continental collision environment beneath Taiwan [Chao et al., 2012], and along transform faults such as the Alpine Fault in New Zealand [Wech et al., 2012], the San Andreas Fault (SAF) near Parkfield, California [Peng et al., 2010; Shelly et al., 2011] and the Oriente Fault near Guantanamo Bay, Cuba [Peng et al., 2013]. In each of these tectonic regimes, tremors are recorded as low-frequency bursts that occur spontaneously (i.e., ambient tremor) or by small stress perturbations due to passing surface waves from distant earthquakes (i.e., triggered tremor) [Peng and Gomberg, 2010].

All Supporting Information may be found in the online version of this article.

${ }^{1}$ School of Earth and Atmospheric Sciences, Georgia Institute of Technology, Atlanta, Georgia, USA.

${ }^{2}$ Earthquake Research Institute, University of Tokyo, Tokyo, Japan.

Corresponding author: Chastity Aiken, School of Earth and Atmospheric Sciences, Georgia Institute of Technology, 311 Ferst Drive, Atlanta, 30332, GA, USA. (chastity.aiken@gatech.edu)

(C2013. American Geophysical Union. All Rights Reserved. 0094-8276/13/10.1002/grl.50220
Compared to ordinary earthquakes, both ambient and triggered tremors exhibit long source durations and are generally located deep within a fault, e.g., $>15 \mathrm{~km}$, beneath the seismogenic zone.

[3] Although tremor has been increasingly observed at many plate boundary faults, it is still not clear what local conditions are necessary for tremors to occur [e.g., Peng and Gomberg, 2010]. In addition, the exact relationship between deep tremors and shallower earthquakes remains to be established. A comprehensive search of tremor around the world could help to better understand the necessary conditions and physical mechanisms of tremor generation, as well as its role during large earthquake cycles.

[4] In this paper, we provide the first evidence of triggered tremor along the Queen Charlotte Margin (QCM), which lies off the northwestern coast of British Columbia in western Canada (Figure 1). The QCM is home to moderate- to large-sized earthquakes. For example, a $M_{s} 8.1$ strike-slip earthquake occurred on 22 August 1949, and more recently, a $M_{w} 7.7$ shallow thrust earthquake occurred beneath the southern QCM on 28 October 2012 (Figure 1). Following our previous approach [e.g., Peng et al., 2013], we examine possible high-frequency tremor signals during the surface waves of teleseismic earthquakes. Searching for triggered tremor is relatively easier than searching for ambient tremor because the amplitude of triggered tremor is generally larger [e.g. Peng et al., 2008; Rubinstein et al., 2007]. In addition to identifying triggered tremors around the QCM, we also locate their sources. Finally, we compare the stress-triggering threshold and amplitude spectra of our earthquakes to other regions where triggered tremors have also been identified.

\section{Study Region}

[5] The QCM extends from the triple junction formed by the Juan de Fuca ridge, the Cascadia subduction zone, and the transform Queen Charlotte Fault (QCF) south of Haida Gwaii (Figure 1). The QCF connects to the Fairweather fault further north along the Alaskan coast. The QCF is a transform boundary between the Pacific plate and the North American plate. These two plates move at a rate of $\sim 5 \mathrm{~cm}$ $\mathrm{yr}^{-1}$ relative to each other [DeMets et al., 2010]. In addition, motion along the QCF does not parallel the relative motion between the Pacific and North American plates, unlike the SAF where motion is mostly pure shear. The discrepancy between the direction of plate motion and the transform QCF is $\sim 22^{\circ}$ [Rohr and Tryon, 2010], which results in a transpressive environment (i.e., transform + compression) with predominant right-lateral strike-slip motion. Such a compressional environment is revealed by the $2012 M_{w} 7.7$ thrust earthquake and its aftershocks (Figure 1). 


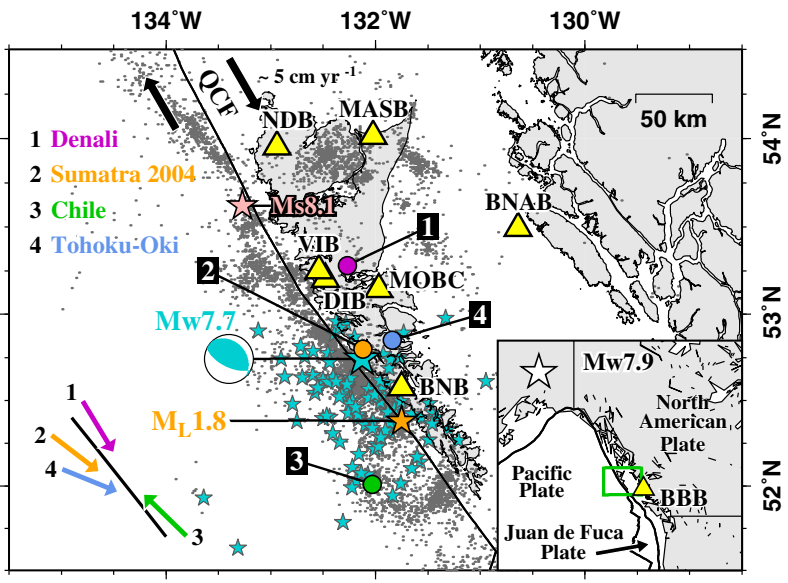

Figure 1. Map view of Queen Charlotte Margin. Thick black lines represent faults/plate boundaries. Black arrows indicate $\sim 5 \mathrm{~cm} \mathrm{yr}^{-1}$ relative plate movement along the QCF. Triangles represent Canadian National Seismograph Network (CNSN) short-period and broadband stations. Numbered/colored circles represent average triggered tremor locations from each triggering earthquake. The pink star marks the epicentral location of the 22 August $1949 M_{s} 8.1$ earthquake. The orange star south of the BNB station marks the location of the $M_{L} 1.8$ earthquake recorded close to the Love wave arrival time of the 2004 Sumatra earthquake. The turquoise star represents the recent 28 October 2012 $M_{w} 7.7$ Queen Charlotte earthquake, and its focal mechanism is indicated. The smaller turquoise stars mark the epicenters of its aftershocks. The bottom left inset depicts the incident angles of surface waves from each earthquake by number and color. The bottom right inset shows the location of the QCM, marked in green, with respect to western Canada and United States as well as the tectonic plates surrounding the QCM. The white star in the inset marks the location of the 03 November $2002 M_{w} 7.9$ Denali Fault earthquake. The location of the BBB station is marked in the inset.

\section{Data and Methods}

[6] We first selected significant earthquakes from the Advanced National Seismic System worldwide catalog accessible from the Northern California Earthquake Data Center. We applied the following criteria to select the earthquakes [Peng et al., 2009; Guilhem et al., 2010]: the events must (1) have occurred during the 1990-2012 period, (2) have magnitude $M \geq 6.5$, (3) have occurred at depths $\leq 100$ $\mathrm{km}$, and (4) occurred at an epicentral distance $\geq 1000 \mathrm{~km}$ from the DIB station. Given these selection criteria, we obtained 745 earthquakes. We then estimated dynamic stresses generated by these earthquakes using surface-wave magnitudes, similar to van der Elst and Brodsky [2010] (see Supporting Information). We only kept earthquakes that generated dynamic stresses greater than $1 \mathrm{kPa}$, which is approximately the minimum tremor triggering threshold identified in other regions [Peng et al., 2009; Rubinstein et al., 2009; Guilhem et al., 2010; Chao et al., 2012]. Eventually, we find 51 such events (Table S1 in Supporting Information).

[7] Next, we retrieved $5 \mathrm{~h}$ of data following the origin times of these 51 earthquakes recorded at the short-period and broadband stations in the Canadian National Seismograph Network (CNSN; accessible via http://www.
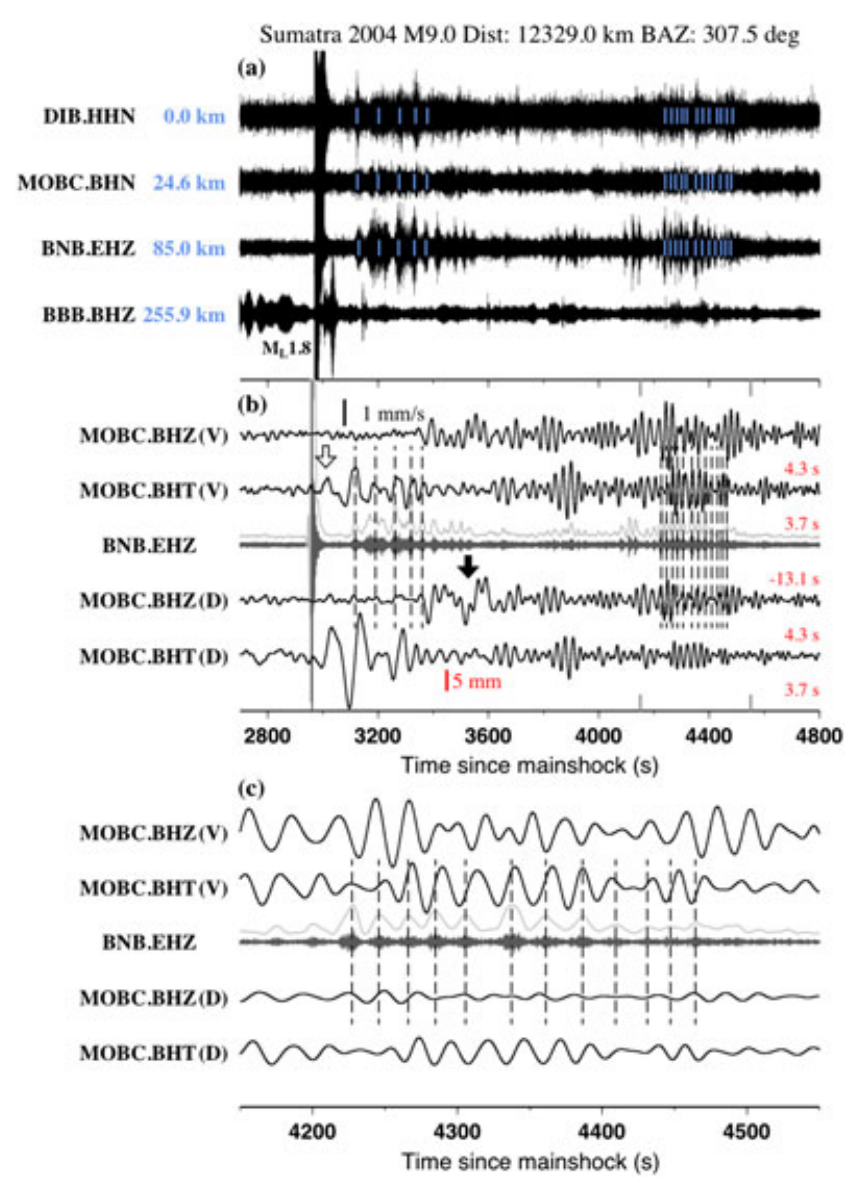

Figure 2. Evidence of tremors triggered in QCM by surface waves from the 26 December $2004 M_{w} 9.0$ Sumatra mainshock as recorded at multiple stations. (a) $5-15 \mathrm{~Hz}$ band-pass filtered velocity seismograms with denoted station names, channels, and along-strike distances with respect to the DIB station. The vertical blue lines indicate the tremor burst peaks handpicked from the filtered envelope functions used for tremor location. (b) A detailed comparison between transverse (BHT) and vertical (BHZ) velocity (V) and displacement (D) seismograms and a $5-15 \mathrm{~Hz}$ band-pass filtered vertical seismogram. Zero-time is the 2004 Sumatra mainshock origin time. Seismograms are time-shifted back to the tremor occurrence time to reflect the relationship between surface waves and tremor at the source region. Adjusted times are marked in red. The $4.1 \mathrm{~km} \mathrm{~s}^{-1}$ Love and $3.5 \mathrm{~km} \mathrm{~s}^{-1}$ Rayleigh wave arrival times are marked by white and black arrows, respectively. Thick, vertical bars mark the amplitude scale of the surface wave velocity (black bar) and displacement (red bar). Vertical dashed lines mark the peaks of tremor envelope functions used for tremor location. (c) Zoom-in of tremors triggered by the subsequent Rayleigh waves.

earthquakescanada.nrcan.gc.ca). We then removed the instrument responses and applied a $5-15 \mathrm{~Hz}$ band-pass filter to capture local tremor activity that may have been triggered by the earthquake. We note that ambient tremor is mostly observed at the frequency range of $1-10 \mathrm{~Hz}$ [e.g., Obara, 2002]. Here, we chose the $5-15 \mathrm{~Hz}$ band mainly because we would like to remove contaminations from the regional and teleseismic $P$ wave signals associated with both the mainshock and large early aftershocks [e.g., Guilhem et al., 2010]. 
Because the signal-to-noise ratio of triggered tremor is generally higher than that of the ambient tremor [Rubinstein et al., 2007; Peng et al., 2008], we can filter the data at a slightly higher frequency band in order to separate local tremor and distant signals. Broadband waveforms without clipped or poorly recorded data were rotated to the great circle path (GCP, radial) and a clockwise $90^{\circ}$ rotation (transverse) direction using the Seismic Analysis Code command "rotate to GCP." After filtering the seismic data, we visually inspected the envelope functions and the three-component filtered seismic data for tremors triggered by the large amplitude surface waves, similar to Chao et al. [2012]. For broadband stations without clipped or poorly recorded data, we computed an average envelope by stacking the radial, transverse, and vertical component envelope functions and dividing by 3 . We identified triggered tremors as non-impulsive, high-frequency signals observable among several stations and coincident with the surface waves of the earthquakes [Peng et al., 2008].

[8] Finally, we located the tremor bursts that were coherent among at least three stations in the QCM using an envelope cross-correlation method [Chao et al., 2013]. Simply, we computed travel time differences based on crosscorrelation of tremor envelopes and then searched for the minimum travel time residual for all possible station pairs using an $S$-wave velocity model for this region [e.g., Table 2 from Bustin et al., 2007]. Since the source depth is not well constrained with this method, we set the depth to be $25 \mathrm{~km}$ based on the location of tremor sources along the transform SAF [e.g., Shelly et al., 2009] and the transpressional Alpine Fault in New Zealand [Wech et al., 2012].

\section{Triggered Tremor Observations}

[9] We observed tremors triggered by surface waves from five large, distant mainshocks (Table S1). Figure 2 shows an example of tremor triggered by the 26 December 2004 $M_{w} 9.2$ Sumatra mainshock as recorded by several stations. Strong tremor bursts are triggered during the Love wave around 3100-3400s and the subsequent Rayleigh wave around 4200-4500 s, with a few weaker tremors occurring
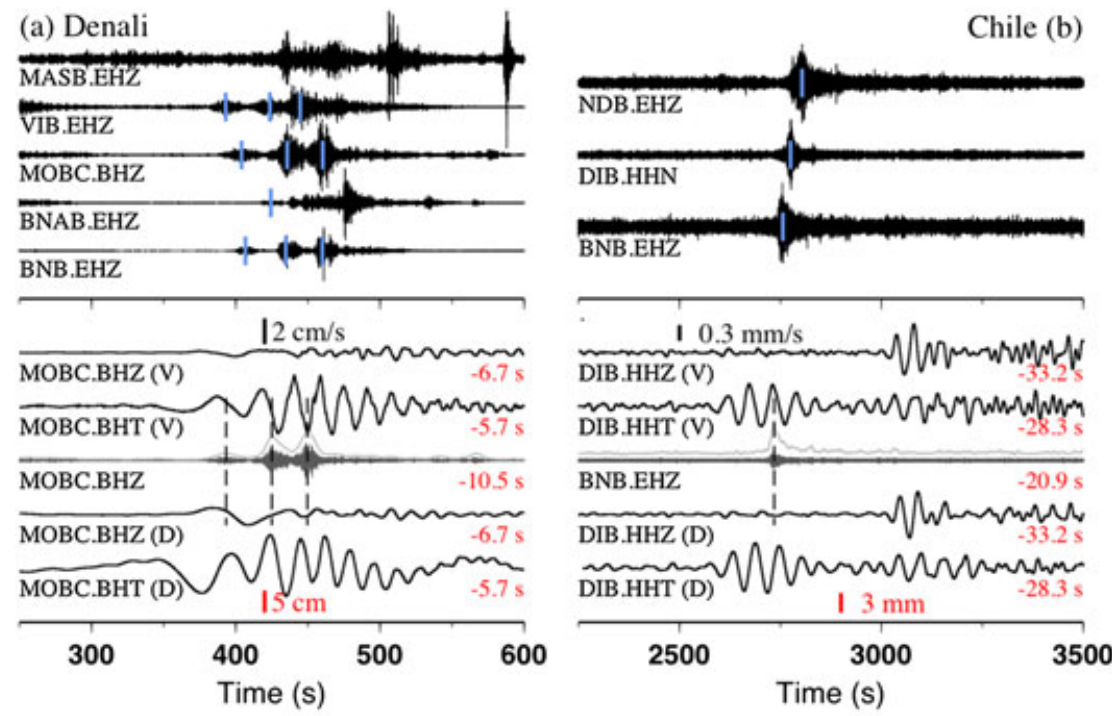

(c) Tohoku-Oki
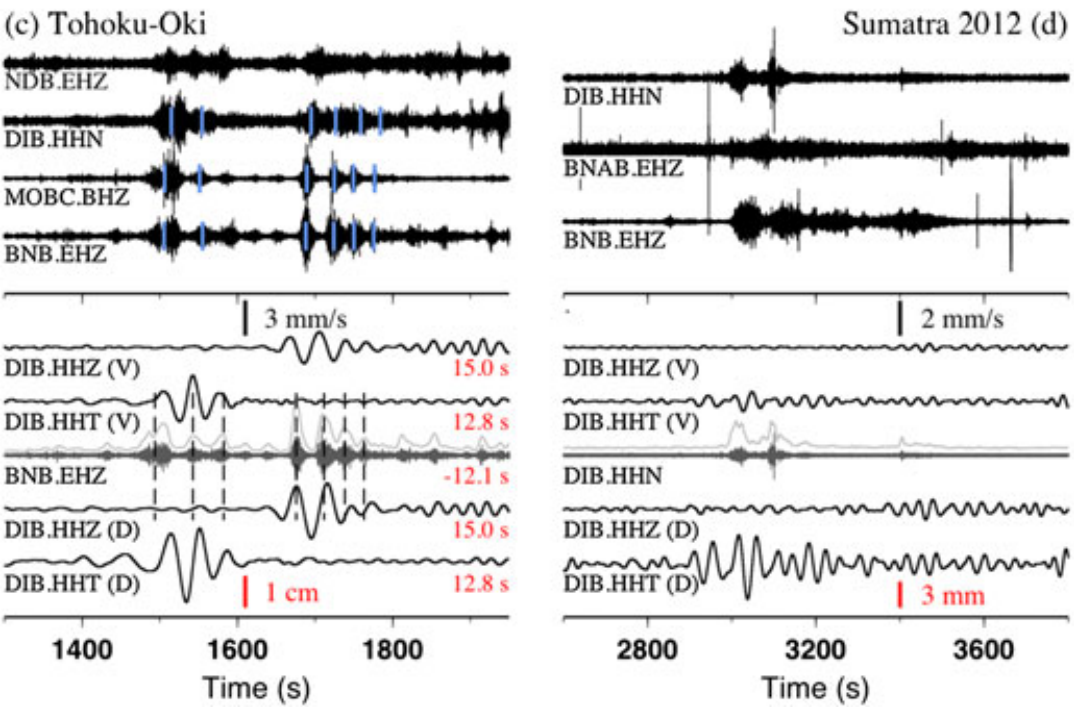

Figure 3. Evidence of tremors triggered by surface waves from several mainshocks as recorded by multiple stations. Symbols and notations are similar to Figure 2. (a) 03 November $2002 M_{w} 7.9$ Denali Fault, (b) 27 February $2010 M_{w} 8.8$ Maule, Chile, (c) 11 March $2011 M_{w} 9.1$ Tohoku-Oki, and (d) 11 April $2012 M_{w} 8.6$ Sumatra earthquakes. 
during the longer period Rayleigh wave around $3500 \mathrm{~s}$. We were able to identify at least 17 tremor bursts, coherent among 3 seismic stations. Similarly, surface waves from the 11 March $2011 M_{w} 9.1$ Tohoku-Oki earthquake triggered tremor, and the triggered tremor was recorded by at least three stations (Figure 3 and Figure S1). Strong tremor bursts are triggered during the Love wave around 1500-1600s and the subsequent Rayleigh wave around 1700-1800 s, with a few weaker tremors occurring during the shorter period Rayleigh waves after $1800 \mathrm{~s}$.

[10] To compare the relationship between the surface waves and tremor signals, we shifted the transverse and vertical components back to the tremor source based on the $4.1 \mathrm{~km} \mathrm{~s}^{-1}$ Love and $3.5 \mathrm{~km} \mathrm{~s}^{-1}$ Rayleigh wave phase velocities [e.g., Rubinstein et al., 2009 and Peng et al., 2009]. Similarly, we shifted a band-pass filtered waveform back to the tremor source based on predicted $S$-wave travel times. For a near strike-parallel incidence on a vertical strike-slip fault, the strike-parallel shear stress is proportional to the Love wave particle velocity [Peng et al., 2008; Hill, 2012] for two reasons. First, the maximum inflection point of Love wave displacement gives rise to maximum dynamic stress with associated double-couple source that either promotes or inhibits shear on the vertical fault place. Second, the maximum inflection point of displacement is equivalent to the maximum velocity. However, for a strike-parallel incidence on a shallow thrust fault, the dip-parallel shear stress is proportional to the Love wave displacement [Rubinstein et al., 2007, 2009]. This is because Love wave displacement is the greatest in the near surface and decreases exponentially with depth, creating a displacement gradient (strain) on a near-horizontal plane. Hence, when the Love wave displacement is in the seaward direction, the overriding plate moves more than the underlying plate, resulting in a positive shear strain that would load and promote thrust failure on the plate interface. When the displacement is in the landward direction, a negative shear strain is induced, which would unload the thrust fault. Because both faulting styles are present at the QCM, we compare the tremor bursts to both velocity and displacement seismograms.
[11] Figure 2 shows that the first five tremor bursts triggered by the 2004 Sumatra mainshock are coherent with the peaks in the Love wave velocity. The latter 12 bursts show a mixed correlation with the transverse velocity and vertical displacement seismograms, with the latter being proportional to the dilatational stress changes [Rubinstein et al., 2009]. In addition to the tremor sequences triggered by the 2011 Tohoku-Oki and 2004 Sumatra earthquakes, we were also able to identify tremors triggered by surface waves of the 03 November $2002 M_{w} 7.9$ Denali Fault earthquake and possibly by the 27 February $2010 M_{w} 8.8$ Maule, Chile and 11 April 2012 $M_{w} 8.6$ Sumatra mainshocks (Figure 3). Tremors triggered by the 2002 Denali Fault earthquake are more coherent with the Love wave displacements (Figure 3a). However, for the 2011 Tohoku-Oki mainshock, the tremor first correlated with the Love wave velocity, and then later with the Rayleigh wave displacement (Figure 3c).

[12] Locations of the triggered tremors are shown in Figure 1. In general, tremors occurred mainly in the southeastern portion of Haida Gwaii and around the QCM (Figure 1 and Table S2). It is also possible that some tremors occurred in the northwestern portion of the island. For example, the tremor signals recorded at station NDB during the 2011 Tohoku-Oki earthquake did not match the move-out for a tremor source radiating from the southeast, which suggests a possible new source. However, we could not locate this source based on one recording. In addition, we were unable to determine accurate locations of tremors possibly triggered by the 2012 Sumatra earthquake because the tremor bursts were not coherently identifiable among at least three stations.

\section{Factors Affecting Triggering Potentials}

[13] Similar to previous systematic studies of dynamically triggered tremors [e.g., Peng et al., 2009], we examined the peak ground velocities (PGVs) of our earthquakes to determine a stress-triggering threshold. Figure $4 \mathrm{a}$ shows the transverse PGVs, dynamic stresses, and back azimuths of all examined earthquakes. The transverse PGVs were
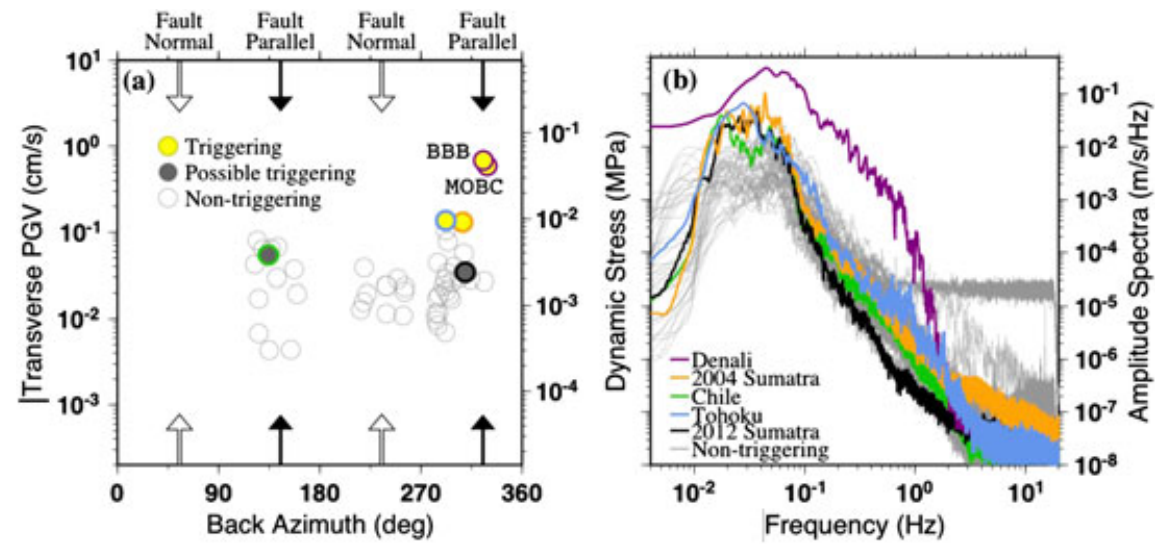

Figure 4. Analysis of peak ground velocities (PGVs) and velocity amplitude spectra. (a) Transverse PGVs and dynamic stresses versus back azimuths of all examined earthquakes. PGVs are low-pass filtered $1 \mathrm{~s}$. Yellow circles represent triggering earthquakes (i.e., 2002 Denali, 2004 Sumatra, and 2011 Tohoku-Oki), gray circles represent possibly triggering earthquakes (i.e., 2010 Chile and 2012 Sumatra), and open circles represent non-triggering earthquakes. (b) Transverse velocity amplitude spectra for all earthquakes examined in this study. Gray lines represent non-triggering earthquakes, and the colored lines represent both triggering and possibly triggering mainshocks. Color indicates event name as used in Figure 1 and Figure 4a. The spectrum that becomes linear at high frequencies is the 22 January 2003 Colima earthquake, and this anomaly is likely due to the recording error as mentioned in Supporting Information. 
measured at station MOBC for earthquakes occurring before 2004 and all others were measured at station DIB. PGVs of the 2002 Denali and 22 January 2003 Colima events were corrected as outlined in the Supporting Information (e.g., Figure S2). In order to avoid contamination of the PGV measurements by high-frequency local seismicity, velocity seismograms were low-passed filtered $1 \mathrm{~s}$ prior to measuring the PGVs. In addition, we examined the surface wave amplitude spectra generated by each earthquake used in this study (Figure 4b). For the amplitude spectra, we first computed the arrival times of the 5 and $2 \mathrm{~km} \mathrm{~s}^{-1}$ wave velocity, cut the transverse velocity data between these times, and then computed the fast Fourier transform (FFT). By computing the FFT between 5 and $2 \mathrm{~km} \mathrm{~s}^{-1}$, the majority of the surface wave energy is captured. Finally, we smoothed the amplitude spectra with a sliding window of 5 points [Peng et al., 2009].

[14] The most promising cases of earthquakes triggering the tremors around the QCM-the 2002 Denali, 2004 Sumatra, and 2011 Tohoku-Oki earthquakes - generated dynamic stresses $>7 \mathrm{kPa}$ and large, long-period (>30 s) amplitude spectra (Figure 4 and Figure S3). In addition, both the Love and Rayleigh waves from these earthquakes triggered tremors. The 2012 Sumatra earthquake, which also generated large, long-period amplitude spectra, may have triggered two tremor bursts with the Love wave. Similarly, the 2010 Chile earthquake possibly triggered one tremor burst with the Love wave. However, it is also possible that the observed tremor during the Chile mainshock could be a coincidence because only one clear burst occurred during the Love wave. In comparison, the long-period (>30s) amplitude spectra of the Chile mainshock are lower than those of the 2002 Denali, 2004 Sumatra, 2011 Tohoku-Oki, and 2012 Sumatra earthquakes. In addition, after applying a lowpass $30 \mathrm{~s}$ filter to the transverse velocity seismograms and measuring the PGVs, most of the earthquakes separate into non-triggering and triggering groups (Figure S4).

\section{Discussion and Conclusions}

[15] In this study, we provided clear evidence of remotely triggered tremors around the QCM. Despite the limited number of seismic stations in this region, we were able to locate the tremor sources of at least four triggered tremor episodes. We set the depth to be at $25 \mathrm{~km}$ because the tremor source depth in other strike-slip regions is $\sim 25-30 \mathrm{~km}$ [e.g., Peng et al., 2009]. Setting the depth may not reflect the true depth of the tremor sources. However, we surmise that the tremors occur deep within the QCM due to the fact that the tremors were coherent at three or more stations within $\sim 100 \mathrm{~km}$ of the DIB station, were coincident with surface waves from earthquakes, and contained relatively low frequencies as compared with regular earthquakes, similar to deep, triggered tremor observed elsewhere [Peng and Gomberg, 2010].

[16] As shown in Figure 1, the tremor was triggered mainly to the east of the QCF beneath Haida Gwaii (Figure 1). Hence, it is tempting to conclude that tremor occurred around the underthrusting plate. Although the dip of the QCF is very close to vertical [Kao et al., 2012], our average horizontal location errors are on the order of $\sim 10 \mathrm{~km}$. Thus, we cannot completely rule out the possibility that tremor occurred on the downward extension of the QCF. In addition, tremor correlated with Love wave displacement for the 2002 Denali Fault earthquake (Figure 3a) and with Love wave velocity for the 2004 Sumatra (Figure 2) and 2011 Tohoku-Oki earthquakes (Figure 3c). These observations also indicate that we cannot rule out either low-angle thrust or vertical strike-slip mechanisms since the triggered tremors are modulated by both displacement and velocity seismograms, respectively [Hill, 2012]. In addition, we found that tremors correlated with dilatational Rayleigh wave stresses, suggesting pore pressure variation as a possible mechanism for tremor generation, which has been proposed in previous studies [e.g., Miyazawa and Brodsky, 2008; Rubinstein et al., 2009; Hill et al., 2013]. Therefore, we cannot make a conclusion on which single faulting style is responsible for the triggered tremor signals and leave this open for a future work.

[17] Previous studies have also suggested that dynamic triggering may be dependent upon amplitude, frequency, and back azimuth of incoming surface waves [Brodsky and Prejean, 2005; Peng et al., 2009, 2010; Guilhem et al., 2010; Chao et al., 2012]. In our study, most of the earthquakes exhibited near strike-parallel incidence with relatively fewer earthquakes having strike-normal incidence. The five earthquakes that have triggered tremor had near strike-parallel incidences. In most cases, tremors were triggered primarily by the Love waves, and additional tremors were triggered by the subsequent Rayleigh waves. This is consistent with the near strike-parallel incidence for many triggering earthquakes and tremors, which tends to produce maximum triggering potential for vertical strike-slip faults and low-angle thrust faults [Hill, 2012]. Moreover, four of the five triggering events produced higher amplitude, longperiod $(>30 s)$ surface waves than non-triggering events (Figure 4). In summary, the fact that these five earthquakes triggered tremor around the QCM could be due to a combination of high PGVs, long-period signals, and near strike-parallel incidence.

[18] We note that none of the events with strike-normal incidence triggered the tremor. This could be caused by the fact that not many large earthquakes from that direction (e.g., southern Pacific) produced large enough PGVs to trigger tremor. Alternatively, they may have triggered weak tremor signals but were undetected by the relatively sparse network in this region. This could also be used to explain that a relatively high peak dynamic stress is needed to trigger $(5-7 \mathrm{kPa})$ in this region, as compared with the $2-3 \mathrm{kPa}$ threshold found along the Parkfield-Cholame section of the SAF [Peng et al., 2009].

[19] Our observations suggest that triggered tremor could occur at many places along major strike-slip faults and subduction zones. Although the necessary conditions for tremor generation are still not clear at this stage, we note that tremor predominantly occurs either in the compressive [e.g., Rubinstein et al., 2007] or transpressive [e.g., this study, Wech et al., 2012; Peng et al., 2009; Peng et al., 2013] tectonic settings. Of course, this could be simply a sampling bias because not many regions with extensional and transextensional tectonic settings have been examined.

[20] As mentioned before, the triggered tremor is not far from the epicenters of the recent 28 October $2012 M_{w} 7.7$ and 22 August $1949 M_{s} 8.1$ Queen Charlotte earthquakes [Lamontagne et al., 2008], the latter of which ruptured a total length of $\sim 500 \mathrm{~km}$ along the QCF. In addition, weak ambient tremor has already been detected beneath the 


\section{AIKEN ET AL.: TREMORS ALONG THE QUEEN CHARLOTTE MARGIN}

QCM (H. Kao, personal communication, 2012). It is still not clear what role tremor plays in large earthquake cycles. Some recent studies suggest that ambient tremor patterns may change immediately before large earthquakes [Shelly, 2009] or may be absent [Gomberg et al., 2012]. Thus, it is critical to improve the seismic instrumentation around the QCM (and elsewhere around the world) to better detect and locate both triggered and ambient tremors. This will not only help to better understand the underlying physical mechanisms responsible for tremor generation along major faults but will also be relevant for seismic hazard analysis.

[21] Acknowledgments. We thank Chunquan Wu, Jacob Walter, and Hongfeng Yang for their useful comments on our manuscript. This material is based upon the work supported by the National Science Foundation Graduate Research Fellowship for C.A. (DGE-1148903). Z.P. and K.C. are supported by the National Science Foundation CAREER (EAR-0956051). K.C. is also supported by the Japan Society for the Promotion of Science (JSPS) through awards P12329 and KAKENHI 23244091.

\section{References}

Beroza, G. C., and S. Ide (2011), Slow earthquakes and nonvolcanic tremor, Annu. Rev. Earth Planet. Sci., 39, 271-296, doi:10.1146/annurev-earth040809-152531.

Brodsky, E. E., and S. G. Prejean (2005), New constraints on mechanisms of remotely triggered seismicity at Long Valley Caldera, J. Geophys. Res., 110, B04302, doi:10.1029/2004JB003211.

Bustin, A. M. M., R. D. Hyndman, H. Kao, and J. F. Cassidy (2007), Evidence for underthrusting beneath the Queen Charlotte Margin British Columbia, from teleseismic receive function analysis, Geophys. J. Int., 171, 1198-1211, doi:10.1111/j.1365-246X.2007.03583.x

Chao, K., Z. Peng, H. Gonzalez-Huizar, C. Aiken, B. Enescu, H. Kao, A. A. Velasco, K. Obara, and T. Matsuzawa (2013), A global search for triggered tremor following the $2011 \mathrm{Mw} 9.0$ Tohoku earthquake, Bull. Seism. Soc. Am., 103(2b), doi:10.1785/0120120171.

Chao, K., Z. Peng, C. Wu, C.-C. Tang, and C.-H. Lin (2012), Remote triggering of non-volcanic tremor around Taiwan, Geophys. J. Int., 188, 301-324, doi:10.1111/j.1365-246X.2011.05261.x

DeMets, C., R. G. Gordon, D. F. Argus (2010), Geologically current plate motions, Geophys. J. Int., 181, 1-80, doi:10.1111/j.1365-246X.2009.04491.x.

Gomberg, J., S. Prejean, and N. Ruppert (2012), Afterslip, tremor, and the Denali Fault earthquake, Bull. Seismo. Soc. Am., 102(2), 892-899, doi:10.1785/0120110142.

Guilhem, A., Z. Peng, and R. M. Nadeau (2010), High-frequency identification of non-volcanic tremor along the San Andreas Fault triggered by regional earthquakes, Geophys. Res. Lett., 37, L16309, doi:10.1029/ 2010GL044660.

Hill, D. P. (2012), Surface-wave potential for triggering tectonic (nonvolcanic) tremor - Corrected, Bull. Seismo. Soc. Am., 102(6), 2313-2336, doi:10.1785/0120120085.

Hill, D. P., Z. Peng, D. R. Shelly, and C. Aiken (2013), S-wave triggering of tremor beneath the Parkfield, CA, section of the San Andreas Fault by the
2011 Tohoku-Oki Japan earthquake: Observations and theory, Bull. Seismo. Soc. Am., 103(2b), doi:10.1785/0120120114.

Kao, H., S.-J. Shan, A. Bent, C. Woodgold, G. Rogers, J. F. Cassidy, and J. Ristau (2012), Regional centroid-moment-tensor analysis for earthquakes in Canada and adjacent regions: An update, Seismol. Res. Lett., 83, 505-515, doi:10.1785/gssrl.83.3.505.

Lamontagne, M., S. Halchuk, J. F. Cassidy, and G. C. Rogers (2008), Significant Canadian earthquakes of the period 1600-2006, Seismo. Res. Lett., 79(2), 211-223, doi:10.1785/gssrl.79.2.211.

Miyazawa, M., and E. E. Brodsky (2008), Deep low-frequency tremor that correlates with the passing surface waves, J. Geophys. Res., 113, B01307, doi:10.1029/2006JB004890.

Obara, K. (2002), Nonvolcanic deep tremor associated with subduction in southwest Japan, Science, 296, 1679-1681, doi:10.1126/science.1070378.

Peng, Z., and J. Gomberg (2010), An integrative perspective of couple seismic and aseismic slow slip phenomena, Nature Geosci., 3, 599-607, doi:10.1038/ngeo940.

Peng, Z., H. Gonzalez-Huizar, K. Chao, C. Aiken, B. Moreno, and G. Armstrong (2013), Tectonic tremor beneath Cuba triggered by the Mw8.8 Maule and Mw9.0 Tohoku-Oki earthquakes, Bull. Seismol. Soc. Am., 103(1), 595-600, doi:10.1785/0120120253.

Peng, Z., D. P. Hill, D. R. Shelly, and C. Aiken (2010), Remotely triggered microearthquakes and tremor in central California following the 2010 $M_{w} 8.8$ Chile earthquake, Geophys. Res. Lett., 37, L24312, doi:10.1029/ 2010GL045462.

Peng, Z., J. E. Vidale, K. C. Creager, J. L. Rubinstein, J. Gomberg, and P. Bodin (2008), Strong tremor near Parkfield, CA, excited by the 2002 Denali Fault earthquake, Geophys. Res. Lett., 35, L23305, doi:10.1029/2008GL036080.

Peng, Z., J. E. Vidale, A. G. Wech, R. M. Nadeau, and K. C. Creager (2009), Remote triggering of tremor along the San Andreas Fault in central California, J. Geophys. Res., 114, B00A06, doi:10.1029/2008JB006049.

Rohr, K. M. M., and A. J. Tryon (2010), Pacific-North America plate boundary reorganization in response to a change in relative plate motion: Offshore Canada, Geochm. Geophys. Geosyst., 11, Q06007, doi:10.1029/ 2009GC003019.

Rubinstein, J. L., J. E. Vidale, J. Gomberg, P. Bodin, K. C. Creager, and S. D. Malone (2007), Non-volcanic tremor driven by large transient shear stresses, Nature, 448, 579-582, doi:10.1038/nature06017.

Rubinstein, J. L., J. Gomberg, J. E. Vidale, A. G. Wech, H. Kao, K. C. Creager, and G. Rogers (2009), Seismic wave triggering of nonvolcanic tremor, episodic tremor and slip, and earthquakes on Vancouver Island, J. Geophys. Res., 114, B00A01, doi:10.1029/2008JB005875.

Shelly, D. R. (2009), Possible deep fault slip preceding the 2004 Parkfield earthquake, inferred from detailed observations of tectonic tremor, Geophys. Res. Lett., 36, L17318, doi:10.1029/2009GL039589.

Shelly, D. R., W. L. Ellsworth, T. Ryberg, C. Haberland, G. S. Fuis, J. Murphy, R. M. Nadeau, and R. Bürgmann (2009), Precise location of San Andreas Fault tremors near Cholame, California using seismometer clusters: Slip on the deep extension of the fault?, Geophys. Res. Lett., 36, L01303, doi:10.1029/2008GL036367.

Shelly, D. R., Z. Peng, D. P. Hill, and C. Aiken (2011), Triggered creep as a possible mechanism for delayed dynamic triggering of tremor and earthquakes, Nature Geosci., 4, 384-388, doi:10.1038/NGEO1141.

van der Elst, N. J., and E. E. Brodsky (2010), Connecting near-field and farfield earthquake triggering to dynamic strain, J. Geophys. Res., 115 B07311, doi:10.1029/2009JB006681.

Wech, A. G., C. M. Boese, T. A. Stern, and J. Townsend (2012), Tectonic tremor and deep slow slip on the Alpine Fault, Geophys. Res. Lett., 39, L10303, doi:10.1029/2012GL051751. 